\title{
Diagnosis and Treatment of AIDS-Related Primary Central Nervous Lymphoma
}

Dai Watanabe*, Yusuke Koizumi, Keishiro Yajima, Tomoko Uehira, and Takuma Shirasaka

AIDS Medical Center, National Hospital Organization Osaka National Hospital, 2-1-14 Hoenzaka, Chuo-ku, Osaka City, Osaka 540-0006, Japan

\begin{abstract}
Summary
Primary central nervous system lymphoma (PCNSL) is an intracranial tumorous lesion that develops in acquired immunodeficiency syndrome (AIDS) patients. PCNSL is very rare, but its prevalence has increased with the expansion of human immunodeficiency virus (HIV) infections. It is diagnosed by imaging or biopsy. Serum and cerebrospinal fluid (CSF) have been analyzed for the presence of diagnostic biomarkers for PCNSL. The presence of Epstein-Barr virus in the CSF is a widely used biomarker, but it has a low positive predictive value. B-cell activation-related cytokines, tumor-specific DNA methylation, and microRNAs have been reported as new candidate biomarkers. Previously, the prognosis of AIDS-related PCNSL was very poor. However, highly active antiretroviral therapy emerged in the late 1990s, which continuously inhibits viral replication and facilitates the recovery of immunity in HIV-infected persons, improving the prognosis of PCNSL patients in combination with whole-brain irradiation. In this review, we focus on the diagnosis of and biomarkers for AIDS-related PCNSL and advancements in its treatment.
\end{abstract}

Keywords: Primary central nervous system lymphoma; AIDS; HIV infection; Biomarkers; Highly active antiretroviral therapy; Wholebrain irradiation

\section{Introduction}

Acquired immunodeficiency syndrome (AIDS) is caused by human immunodeficiency virus (HIV) infection. HIV infects CD4-positive T lymphocytes and destroys the immune system by reducing the number of these lymphocytes. The resulting reduced immunity facilitates the occurrence of opportunistic infections, such as Pneumocystis pneumonia, cytomegalovirus retinitis, and toxoplasma encephalopathy. In AIDS patients, the risk of opportunistic malignant tumors, such as Kaposi's sarcoma, uterine cervical cancer, and non-Hodgkin's lymphoma (NHL), also increases. NHL in HIV-infected persons is divided into systemic NHL and primary central nervous system lymphoma (PCNSL). PCNSL is characterized by the localization of lesions only in the central nervous system (CNS). AIDS is diagnosed when these specific opportunistic infections and malignant tumors develop in HIV-infected persons. AIDS was previously a fatal disease; however, in the late 1990s, highly active antiretroviral therapy (HAART) was developed and improved the prognosis of HIV-infected persons. The combination of several anti-HIV agents continuously inhibits HIV replication in the body, facilitating the recovery of the immune system.

PCNSL was a very rare tumor before the outbreak of HIV, accounting for $<1 \%$ of intracranial tumor cases and $1-2 \%$ of NHL cases [1]. The outbreak of HIV in the early 1980s increased the incidence of AIDS-related PCNSL because HIV-infected persons have an increased risk of developing PCNSL. The incidence rate of AIDS-related PCNSL was much higher than that of non-HIV related PCNSL (3-8 per 1,000 person-years among HIV-infected persons vs. 5-10 per 1,000,000 person-years) [2-4]. The incidence of non-HIV-related PCNLS also increased. Currently, PCNSL are estimated to account for $1-5 \%$ of all brain tumors.

In the pre-HAART era, the prognosis of AIDS-related PCNSL was very poor [5]; however, after the development of HAART, several studies reported an improvement in the prognosis of AIDS-related PCNSL patients [6-8]. In addition, the number of PCNSL patients markedly decreased with the advancement of HAART. In the report by Diamond et al., the absolute incidence rate of PCNSL among AIDS patients declined from 8.4 per 1,000 person-years pre-HAART to 1.1 per 1,000 person-years post-HAART [9]. Other studies also reported a dramatic reduction in its incidence $[2,3,7,10-13]$ and prevalence [14] in the HAART era. However, AIDS-related PCNSL develops in cases with markedly reduced immunity [15], and its treatment and diagnosis are frequently difficult because of the presence of multiple opportunistic infections and malignant tumors or the poor condition of the system, reducing diagnostic and therapeutic choices. In this review, we focus on the diagnosis, treatment, and biomarkers for AIDS-related PCNSL together with the progress in elucidating the developmental mechanism.

\section{Diagnostic procedure}

In HIV-infected persons, PCNSL forms intracranial masses at a frequency second to toxoplasma encephalopathy [16]. Generally, PCNSL develops when immunity markedly declines in patients previously diagnosed with AIDS [15]. Systemic NHL may develop even though the number of CD4-positive T lymphocytes is maintained; however, the count is $<50$ cells $/ \mu \mathrm{L}$ in most cases of PCNSL $[17,18]$. To differentiate PCNSL from systemic NHL, an investigation of the whole body is necessary on diagnosis. When the presence of an intracranial mass is suspected on the basis of the symptoms, a computed tomography (CT) or magnetic resonance imaging (MRI) scan of the brain is performed; however, MRI has a higher diagnostic value than CT [19]. In a retrospective analysis of 28 patients with AIDS-related PCNSL, MRI revealed 66 lesions, whereas CT showed 45 lesions, indicating the superior sensitivity of MRI [20]. On CT, shadows of masses with

*Corresponding author: Dai Watanabe, AIDS Medical Center, National Hospital Organization Osaka National Hospital, 2-1-14 Hoenzaka, Chuo-ku, Osaka 5400006, Japan, Tel: +81-6-6942-1331; Fax: +81-6-6946-3652;E-mail:dai@onh.go.jp

Received October 22, 2011; Accepted November 19, 2011; Published November 20, 2011

Citation: Watanabe D, Koizumi Y, Yajima K, Uehira T, Shirasaka T (2011) Diagnosis and Treatment of AIDS-Related Primary Central Nervous Lymphoma. J Blood Disord Transfus S1:001. doi:10.4172/2155-9864.S1-001

Copyright: (c) 2011 Watanabe D, et al. This is an open-access article distributed under the terms of the Creative Commons Attribution License, which permits unrestricted use, distribution, and reproduction in any medium, provided the original author and source are credited. 
a contrast effect are observed, but toxoplasma encephalopathy also shows a similar feature in AIDS patients [21]. On MRI, enhancement is observed similarly to that in CT. Multiple masses with irregular margins and heterogeneous enhancement are detected in many cases [20,22]. ${ }^{18} \mathrm{~F}$-fluorodeoxyglucose-positron emission tomography (FDG-PET) is also useful for diagnosis. In a review of 166 PCNSL cases, only FDGPET detected abnormalities, while no abnormalities were detected with various other examinations in $8 \%$ of cases [23]. The association of FDG-PET findings with malignancy and the activity levels of lymphoma lesions have also been reported [24,25]. When no diagnosis can be made by either method or there is no response to experiencebased treatment for toxoplasmosis, a brain biopsy is taken. Diagnosis by brain biopsy is definite, but it is not a necessarily safe procedure. It is difficult to perform when the systemic condition is poor or depending on the anatomical position of the lesion. The histologic type was diffuse large B-cell lymphoma (DLBCL) in $~ 90 \%$ of cases [26], but T-cell lymphoma and anaplastic large cell lymphoma were noted in rare cases. Epstein-Barr virus (EBV) was absent in PCNSL lesions in cases that retained immunity, but EBV infection was confirmed in almost all cases of AIDS-related PCNSL [27-29].

\section{Diagnosis of PCNSL based on EBV-DNA detection in the CSF}

EBV is detected in AIDS-related systemic NHL tissue in 50\% of patients, whereas it is detected in almost all patients with AIDS-related PCNSL. Therefore, many studies on the possibility of diagnosing AIDSrelated PCNSL by detecting EBV in the CSF have been performed. In studies performed in the 1990s involving AIDS patients, EBV-DNA detection in the CSF employing PCR showed a high sensitivity (83$100 \%)$ with regard to the diagnosis of AIDS-related PCNSL [30-35]. The specificity was also high $(91-100 \%)$, and it has been reported that EBV-DNA was only detected in the CSF of a small number of HIVinfected persons, excluding patients with PCNSL and CNS invasion by systemic NHL. On the basis of these findings, EBV-DNA detection in the CSF was previously regarded as a basis for diagnosing PCNSL in cases in which a biopsy could not be performed, despite PCNSL being suspected on imaging. However, in later studies, the detection of EBVDNA in the CSF using PCR was not rare in HIV-infected persons, being detected in $\sim 20 \%$ of patients [36-38], indicating the presence of a problem regarding the specificity of this technique ( $\sim 80 \%)$. EBVDNA was also detected in the CSF of $\sim 4 \%$ of non-HIV-infected patients with cerebral diseases and without typical symptoms of viral infection of the CNS (such as bacterial meningitis and cerebral hemorrhage) [39]. Since EBV was more frequently detected in the CSF than other herpes viruses and the JC virus, EBV may be readily reactivated subclinically in the CNS regardless of the presence or absence of HIV infection $[36,37,39]$. EBV-induced encephalitis and myelitis and CNS lymphomatoid granulomatosis (LYG) have also been reported in HIVinfected persons, and all of these patients were positive for CSF EBVDNA [40-42]. Attention should be paid to the fact that EBV-DNA is detected in the CSF of not only patients with tumors but also those with EBV-induced infectious diseases of the CNS. In a patient with CNS LYG, findings similar to those of PCNSL were noted on MRI (Figure 1). The clinical characteristics of this patient are summarized in Table 1.

The ratio of PCNSL patients to subjects in whom EBV-DNA is detected in the CSF, i.e., the positive predictive value (PPV), is not high. Ivers et al. reported that the PPV was only 29\% [38]. In addition to the specificity problem described above, reduced prevalence may also be involved in the low PPV [14]. The development of HAART in the late 1990s facilitated the recovery of immunity by continuously inhibiting

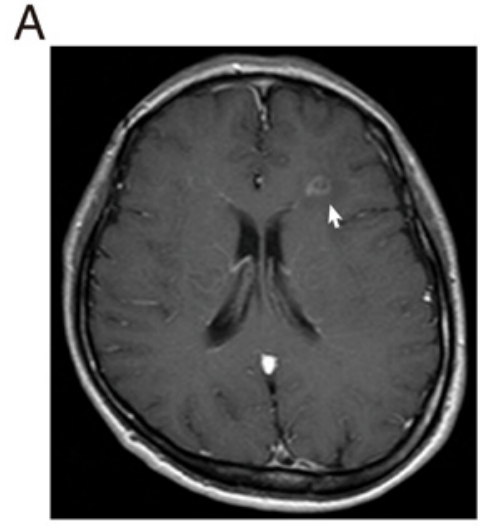

B

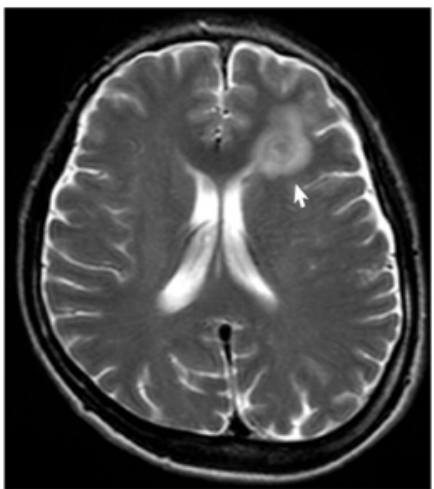

Figure 1: MRI findings of CNS LYG in an HIV-infected person. A: Gadolinium-enhanced T1-weighted MRI reveals a ring-enhanced lesion resembling PCNSL (arrow). B: T2-weighted MRI.

\begin{tabular}{|l|l|l|}
\hline Age $($ years $)$ & & 42 \\
\hline Sex & & Male \\
\hline CD4 cell count $(/ \mu \mathrm{L})$ & 33 \\
\hline $\begin{array}{l}\text { Plasma HIV-RNA (copies/ } \\
\mathrm{mL})\end{array}$ & 410000 \\
\hline $\mathrm{CSF}$ & EBV-DNA (copies $/ \mathrm{mL})$ & 1300 \\
\hline Biopsy specimen & EBV* & $(+)$ \\
\hline & IgH gene rearrangement & $(-)$ \\
\hline
\end{tabular}

*Epstein-Barr virus (EBV) was detected using EBV-encoded RNA in-situ hybridization. CSF, cerebrospinal fluid; IgH, immunoglobulin heavy chain.

Table 1: Clinical characteristics of CNS LYG in an HIV-infected patient.

\begin{tabular}{|c|c|c|c|}
\hline Biomarkers & References & & \\
\hline \multirow{3}{*}{ Cytokines } & Interleukin & IL-10 & {$[32,51]$} \\
\hline & $\begin{array}{l}\text { Immune activation } \\
\text { markers }\end{array}$ & soluble CD $27^{* 1}$ & {$[53]$} \\
\hline & Chemokine & CXCL13 $3^{* 1}$ & [52] \\
\hline DNA & $\begin{array}{l}\text { Tumor-specific } \\
\text { DNA methylation }\end{array}$ & $\begin{array}{l}\text { DAPK, p16, } \\
\text { MGMT, p14, p73, } \\
\text { etc }^{* 2}\end{array}$ & [63] \\
\hline RNA & miRNAs & $\begin{array}{l}\text { miR-17-92 cluster } \\
\text { and miR2 } 21^{* 1}\end{array}$ & [79] \\
\hline
\end{tabular}

*1These biomarkers were tested in the CSF of non-HIV-related PCNSL patients. *2 Tumor-specific methylated DNA in the CSF was not investigated. CSF, cerebrospinal fluid; IL-10, interleukin-10; miRNAs, microRNAs.

Table 2: Biomarker candidates in the CSF for diagnosing AIDS-related PCNSL

HIV replication, which may have reduced the prevalence of AIDSrelated PCNSL, thereby decreasing the PPV.

Comparisons between the quantitative and qualitative detection of 
EBV-DNA in the CSF have been made [43]. An improvement of the specificity and PPV by setting the cut-off value of quantitative detection at 10,000 copies/mL has been reported, but the report included only 2 cases of AIDS-related PCNSL; therefore, it cannot be concluded whether this cut-off value is appropriate. To establish the optimum cutoff value, it is necessary to analyze a large number of cases. On the basis of the above findings, the absence of EBV-DNA in the CSF detected using PCR provides useful information to exclude AIDS-related PCNSL because of the high detection sensitivity of this technique. However, in the current situation, with a reduced prevalence and low $\mathrm{PPV}$, it is considered that a highly specific biomarker is necessary to diagnose AIDS-related PCNSL. Potential biomarkers for diagnosing AIDS-related PCNSL are discussed below (Table 2).

\section{AIDS-related PCNSL and cytokines}

Cytokines are intercellular signal transmission molecules that regulate the differentiation, proliferation, and activation of immunocytes. They are mainly secreted by immunocytes and act on receptors expressed on the surface of target cells. The action of cytokines is then exhibited through specific signal transduction pathways in the target cells. Typical cytokine proteins include the tumor necrosis factor (TNF), interferon, and interleukin (IL) families. These cytokines form complex networks that additively or antagonistically control the immune system. The abnormal expression of various cytokines in HIV-infected patients has been reported. Although HAART reduces the plasma HIV-RNA level to below the detection limit, the circulating cytokine levels are not completely normalized $[44,45]$. The abnormal activation of B cells by these cytokines is considered to be involved in the development of B-cell lineage NHL.

The serum levels of cytokines involved in B-cell activation and cytokine-related immune activation markers and the risk of developing AIDS-related systemic NHL have been investigated in detail. The elevation of the serum levels of IL-6, IL-10, CXCL13, soluble TNF-R1, soluble CD27, and soluble CD30 prior to systemic NHL development in HIV-infected persons has been reported [46-48]. Of these studies, Breen et al. simultaneously investigated the risk of PCNSL and systemic NHL, but they did not identify any cytokines involved in the risk of developing PCNSL [48]. On the other hand, studies on cytokine gene polymorphisms and the risk of AIDS-related NHL showed that the risk of PCNSL decreased in the presence of either the IL-10 rs1800871 $\mathrm{T}$ allele or the IL-10 rs1800872 A allele [49]. These IL-10 promoter polymorphisms were involved in the reduction of IL-10 serum levels [50].

In addition to those in serum, it has been investigated whether cytokines and cytokine-related immune activation markers in the CSF serve as biomarkers for diagnosing PCNSL. In patients with AIDS-related PCNSL, the elevation of IL-10 levels in the CSF, which is secreted by Th2 cells and promotes antibody production by B cells, has been reported [32,51]. The levels of CXCL13, with B-cell-selective chemotactic activity [52], and soluble CD27, which belongs to the TNF receptor superfamily [53], were elevated in patients with non-HIVrelated PCNSL. However, the rise in their levels was not tumor-specific. The levels of IL-10 in the CSF were also elevated in HIV-infected patients with cryptococcal meningitis and HIV encephalopathy [54]. In a report examining the levels of soluble CD27 in the CSF, no significant difference was noted between patients with PCNSL and those with inflammatory disease of the CNS [53]. Therefore, although B-cell- related cytokines are involved in the pathogenesis of AIDS-related PCNSL, it may be difficult to differentiate PCNSL and inflammatory lesions by measuring the levels of cytokines in the CSF.

\section{AIDS-related PCNSL and tumor-specific DNA methylation}

Malignant tumors may be induced by viral infection and inflammation; however, abnormalities of oncogenes and antioncogenes also have a role in their pathogenesis. These abnormalities are classified into genetic aberrations due to mutations and deletions and epigenetic aberrations due to the chemical modification of bases. Epigenetic gene aberrations act on the regulation of gene transcription, and the most common epigenetic change is the methylation of genomic DNA. In malignant tumor cells, anti-oncogenes are silenced, and the association between this silencing and aberrant methylation of CpG islands in the promoter region has been shown. Actually, many reports have described the aberrant methylation of the promoter regions of various anti-oncogenes, such as $\mathrm{Rb}$ and $\mathrm{p} 16$, in malignant tumors, and the detection of CpG island methylation of cancer-related genes in tumor cell-derived DNA in PCNSL has also been reported. The majority of these reports focused on 1 to several cancer-related genes [55-62]. Chu et al. investigated the DNA methylation status of 14 antioncogenes using methylation-specific PCR in 25 PCNSL patients, including 2 HIV-infected patients. DNA methylation was detected in death-associated protein kinase (DAPK) in 84\% of samples, p16 in 64\%, and O6-methylguanine-methyltransferase (MGMT) in 52\%, showing that methylation was noted in 1 of these 3 genes in $96 \%$ of samples [63].

The detection of tumor-specific DNA methylation is considered to be a biomarker for early diagnosis. In addition to the detection of DNA methylation in serum and plasma samples from cancer-bearing patients [64], it was detected in sputum samples from lung cancer patients [65] and urinary sediment samples from prostate cancer patients [66], showing the usefulness of detecting DNA methylation for early diagnosis. Since PCNSL is localized in the CNS, it may be ideal to detect DNA methylation in the CSF, rather than peripheral blood. However, aberrant DNA methylation was detected in the serum $[67,68]$ and plasma [69], in addition to the CSF [68], in $>50 \%$ of patients with glioma, a malignant tumor arising in the CNS, similarly to PCNSL, and it has been proposed that the detection of DNA methylation in peripheral blood and body fluid samples serves as a biomarker for PCNSL [63]. Furthermore, the detection of DNA methylation is associated with prognosis, in addition to early diagnosis. The presence of MGMT methylation is important to predict the reaction of patients to alkylating agents [70].

The comprehensive analysis of DNA methylation using arrays has recently been performed. Systemic DLBCL was divided into activated $\mathrm{B}$-cell (ABC) and germinal center $\mathrm{B}$ (GCB) types, and the gene expression pattern differed between these types [71]. The prognosis of ABC-DLBCL was poor [72]. Differences in the DNA methylation pattern, in addition to differences in the expression pattern, have also been clarified using comprehensive DNA methylation analysis [73]. To investigate differences in the molecular mechanisms between PCNSL and systemic DLBCL, Richter et al. compared comprehensive DNA methylation patterns between 5 PCNSL and 49 systemic DLBCL patients [74]. Although tumor-specific DNA methylation was noted in both groups, there was no significant difference between the groups.

Studies on DNA methylation detection in malignant tumors and its significance have progressed rapidly, but most reports on PCNSL 
involved patients with normal immunity [55-60,62,74]. Since no study has focused on AIDS-related PCNSL, the influences of HIV and EBV infections on DNA methylation have not been clarified. Moreover, DNA methylation in AIDS-related systemic NHL has been investigated in only 2 reports [75,76]. The analysis of many AIDS patients is complicated by the simultaneous presence of several opportunistic infections and malignant tumors. Imaging diagnosis is difficult when several lesions are present in the same organ. It is impossible to adopt EBV-DNA detection and cytokine level elevation in the CSF as tumorspecific biomarkers to diagnose PCNSL because of the specificity problem and the concomitant presence of inflammatory disease. The use of tumor-specific DNA methylation as a biomarker is reasonable in this regard, and further advancement of research on HIV infection in this field is expected.

\section{MicroRNAs as new biomarker candidates}

MicroRNAs (miRNAs) are a type of non-coding RNA that are not translated into protein. Precursor RNA transcribed from DNA goes through various processing stages, and, finally, miRNAs, 20-25-base, single-stranded RNAs, are produced. These miRNAs bind to the 3 '-end of the non-translated regions of specific messenger RNAs (mRNAs), and gene expression is regulated by the degradation of mRNAs and the inhibition of mRNA translation. miRNAs are important regulators of cell function, such as proliferation, differentiation, and apoptosis, and they can also function as oncogenes or anti-oncogenes. Actually, the abnormal expression of miRNAs in various malignant tumors, including lung and breast cancers, has been reported [77]. Abnormal miRNA expression in AIDS-related PCNSL has also recently been reported [78]. Thapa et al. investigated miRNA expression in lesions from 24 AIDS-related NHL patients, including 5 PCNSL patients, using a real-time PCR approach, and observed that the expression of the miR17-92 cluster, which encodes 7 miRNAs including miR-19 and miR-92, was commonly enhanced in AIDS-related NHL patients. Baraniskin et al. measured the expression of miRNAs in the CSF of 23 patients with non-AIDS-related PCNSL [79]. Compared to patients with CNS inflammation and other diseases, the levels of miR-21, miR-19, and miR-92a in the CSF were significantly increased in PCNSL patients. It has been reported that PCNSL could be diagnosed at a sensitivity and specificity of 95.7 and $96.7 \%$, respectively, by measuring the expression of these 3 miRNAs. It is also interesting to note that these 2 reports included the same miRNAs. Although only a few studies have assessed the expression of miRNAs in AIDS-related PCNSL, the expression levels of miRNAs in the CSF may represent new candidate biomarkers [80].

\section{Treatment}

Other than in AIDS patients, PCNSL may develop in immunocompetent persons, although this phenomenon is rare. In a previous study comparing AIDS-related and non-AIDS-related PCNSL, the median survival time (MST) was 0.9 months (vs. 2.7 months) in the untreated group and 3.0 months (vs. 16.6 months) in the radiation group, apparently showing the poor prognosis of the former [81]. However, these findings may have been due to major differences in the patients' backgrounds, such as the biological properties of tumors, immunity, and concomitant infections, despite both types of tumor being lymphoproliferative disease. As described above, EBV was detected in PCNSL lesions in many AIDS patients, but not in the lesions of patients with normal immunity. The primary treatment for non-AIDS-related PCNSL has progressed from radiotherapy alone to chemotherapy with methotrexate alone, multidrug chemotherapy, or the combination of chemotherapy + radiotherapy. In contrast, AIDSrelated PCNSL was treated with radiotherapy alone in most reports, and chemotherapy was performed in fewer reported cases. The prevalence of AIDS-related PCNSL peaked in the 1980s to the early half of the 1990s before the appearance of HAART, and the number of patients rapidly decreased thereafter, influencing the state of treatment.

Radiotherapy was the initial sole treatment for AIDS-related PCNSL, and it prolonged the survival of patients to some extent (Table 3 ). However, it was not curative, and recurrence frequently occurred inside and outside of the irradiated region. Formenti et al. irradiated the whole brain of 10 AIDS-related PCNSL patients, and achieved temporary complete remission (CR) in 6 patients; 2 patients irradiated with 50 Gy survived for more than 1 year, but those irradiated at a lower dose died within several months due to opportunistic infections and tumor recurrence [82]. Baumgartner et al. reported that 17 and $52 \%$ of 29 AIDS-related PCNSL patients irradiated at 30-54 Gy achieved a CR and a partial response (PR), respectively, and the MST was 119 days (vs. 27 days in the non-irradiated group). The cause of death was mostly aggravation of PCNSL in the non-irradiated group and opportunistic infections in the irradiated group [83]. Goldstein et al. irradiated 17 AIDS-related PCNSL patients at 5.4-57 Gy, and the MST was 72 days. The radiation dose was not related to the outcome, but the performance status (PS) before treatment was related (MST: 226 days in the group with a favorable Karnovsky PS vs. 59 days in the poor PS group) [21].

These reports in the 1990s clarified that AIDS-related PCNSL is relatively sensitive to radiotherapy; however, the survival time was only several months, even though the tumor was radiation-sensitive and reduced in size, and most patients died of opportunistic infections. HIV infection-induced immunodeficiency may have markedly influenced the outcome.

With the development of HAART, the therapeutic effect of radiotherapy has also increased. Hoffmann et al. reported that the survival times of groups treated with a combination of HAART and radiation (30-50 Gy) and radiation alone and an untreated group were 1,093,132, and 33 days, respectively, showing that HAART and radiotherapy were independent factors involved in long-term survival [6]. HAART was shown to be a stronger prognostic factor than radiotherapy in another report [84]. Newell et al. reported that the therapeutic results were significantly more favorable in the group diagnosed after 1993 out of patients observed between 1987 and 1998 , and the incidence rapidly decreased after 1997 [7]. In the latest report, 23 PCNSL patients diagnosed between 2002 to 2008 were treated with HAART [8]; 21 patients were treated with radiotherapy alone,

\begin{tabular}{|l|l|l|l|l|l|}
\hline Authors (Year) & Cases & HAART & $\begin{array}{l}\text { Radiation } \\
\text { dose (Gy) }\end{array}$ & MST & References \\
\hline Formenti et al. (1989) & 10 & $(-)$ & $22-50$ & $\begin{array}{l}5.5 \\
\text { months }\end{array}$ & {$[82]$} \\
\hline Baumgartner et al. (1990) & 29 & $(-)$ & $30-54$ & 119 days & {$[83]$} \\
\hline Goldstein et al. (1991) & 17 & $(-)$ & $5.4-57$ & 72 days & {$[21]$} \\
\hline Hoffman et al. (2001) & 7 & $(-)$ & $30-50$ & 132 days & {$[6]$} \\
\hline & 5 & $(+)$ & $30-50$ & 1093 days & \\
\hline Skiest et al. (2003) & 18 & $(-)$ & N.A. & 52 days & {$[84]$} \\
\hline & 7 & $(+)$ & N.A. & $\begin{array}{l}>667 \\
\text { days* }\end{array}$ & \\
\hline Nagai et al. (2010) & 13 & $(+)$ & $\geq 30$ & 60 months & {$[8]$} \\
\hline
\end{tabular}

*MST not reached at a median follow-up time of 667 days. N.A., data not available; MST, median survival time.

Table 3: Major radiation therapy results for PCNSL with or without HAART. 
the $\mathrm{CR}+\mathrm{PR}$ rate including $1 \mathrm{BSC}$ patient and 1 patient treated with chemotherapy and radiotherapy was $65 \%$, and the 3 -year survival rate was $64 \%$, showing a markedly favorable outcome. A favorable PS (MST: 48 months in the ECOG PS0-2 group vs. 2 months in the PS3-4 group) and a $\geq 30-G y$ radiation dose (MST: 60 months vs. 2 months in cases irradiated at $<30 \mathrm{~Gy}$ ) were favorable prognostic factors. The age and $\mathrm{CD} 4$ count were considered to be prognosis-determining factors in previous reports, but these showed no influence.

A standard treatment for non-AIDS-related PCNSL, high-dose methotrexate (MTX) therapy, has also been investigated in AIDSrelated PCNSL patients [85]. In a non-controlled study involving 15 patients, MTX $(3 \mathrm{~g} / \mathrm{m} 2)$ was administered every 14 days for a maximum of 6 cycles. The response rate was $47 \%$ and the overall MST was 290 days, but when limited to 10 histologically diagnosed cases, the MST was 73 days. In addition, HAART, including a protease inhibitor, was performed in 5 of 7 patients who responded to treatment, and all these patients survived. These findings suggested that HAART with stronger anti-HIV activity further increased the response rate to MTX therapy; however, there has been no follow-up study. Therefore, judgment of this treatment should be reserved. Chemotherapy, including multidrug therapy with other drugs, had only been reported occasionally until the early 1990s, and many cases showed failure.

Overall, the combination of HAART and irradiation improved the outcome, but attention should also be paid to the presence of case reports in which HAART alone achieved CR of AIDS-related PCNSL [86] and the problem of leukoencephalopathy induced by whole-brain irradiation [8]. It may be difficult to arrive at a conclusion regarding the therapeutic effects of combinations of HAART + chemotherapy and HAART + chemotherapy + radiotherapy because the number of PCNSL patients has markedly decreased with the advancement of HAART.

\section{Conclusion}

This review described the latest information concerning the diagnosis, treatment, and biomarkers of PCNSL. Since the PPV of EBVDNA detected in the CSF using PCR is not so high, the development of other biomarkers is expected. B-cell-related cytokines, tumor-specific DNA methylation, and miRNAs are also closely associated with the pathology of PCNSL and are expected to serve as new biomarkers. The combination of HAART and radiation improved the outcome of AIDS-related PCNSL, but the optimum combination of HAART, radiotherapy, and chemotherapy has not been clarified and remains to be investigated.

\section{Acknowledgments}

This work was supported by Grants-in-Aid for AIDS research to TU from the Ministry of Health, Labor, and Welfare of Japan (No. H23-AIDS-I-002).

\section{References}

1. Hochberg FH, Miller DC (1988) Primary central nervous system lymphoma. J Neurosurg 68: 835-853

2. Besson C, Goubar A, Gabarre J, Rozenbaum W, Pialoux G, et al. (2001) Changes in AIDS-related lymphoma since the era of highly active antiretroviral therapy. Blood 98: 2339-2344.

3. Kirk O, Pedersen C, Cozzi-Lepri A, Antunes F, Miller V, et al. (2001) Non-Hodgkin lymphoma in HIV-infected patients in the era of highly active antiretroviral therapy. Blood 98: 3406-3412.

4. Pulido JS, Vierkant RA, Olson JE, Abrey L, Schiff D, et al. (2009) Racial differences in primary central nervous system lymphoma incidence and survival rates. Neuro-oncology 11: 318-322.

5. Freeman CR, Shustik C, Brisson ML, Meagher-Villemure K, Dylewski I (1986)
Primary malignant lymphoma of the central nervous system. Cancer 58: 1106 1111.

6. Hoffmann C, Tabrizian S, Wolf E, Eggers C, Stoehr A, et al. (2001) Survival of AIDS patients with primary central nervous system lymphoma is dramatically improved by HAART-induced immune recovery. AIDS 15: 2119-2127.

7. Newell ME, Hoy JF, Cooper SG, DeGraaff B, Grulich AE, et al. (2004) Human immunodeficiency virus-related primary central nervous system lymphoma: factors influencing survival in 111 patients. Cancer 100: 2627-2636.

8. Nagai H, Odawara T, Ajisawa A, Tanuma J, Hagiwara S, et al. (2010) Whole brain radiation alone produces favourable outcomes for AIDS-related primary central nervous system lymphoma in the HAART era. Eur J Haematol 84: 499505

9. Diamond C, Taylor TH, Aboumrad T, Anton-Culver H (2006) Changes in acquired immunodeficiency syndrome-related non-Hodgkin lymphoma in the era of highly active antiretroviral therapy: incidence, presentation, treatment, and survival. Cancer 106: 128-135.

10. Ammassari A, Cingolani A, Pezzotti P, De Luca DA, Murri R, et al. (2000) AIDS-related focal brain lesions in the era of highly active antiretroviral therapy. Neurology 55: 1194-1200.

11. Wolf T, Brodt HR, Fichtlscherer S, Mantzsch K, Hoelzer D, et al. (2005) Changing incidence and prognostic factors of survival in AIDS-related nonHodgkin's lymphoma in the era of highly active antiretroviral therapy (HAART). Leuk Lymphoma 46: 207-215.

12. Bower M, Powles T, Nelson M, Mandalia S, Gazzard B, et al. (2006) Highly active antiretroviral therapy and human immunodeficiency virus-associated primary cerebral lymphoma. J Natl Cancer Inst 98: 1088-1091.

13. Haldorsen IS, Krakenes J, Goplen AK, Dunlop O, Mella O, et al. (2008) AIDSrelated primary central nervous system lymphoma: a Norwegian national survey 1989-2003. BMC Cancer 8: 225.

14. Cinque $P$, Cingolani A, Bossolasco S, Antinori A (2004) Positive predictive value of Epstein-Barr virus DNA detection in HIV-related primary central nervous system lymphoma. Clin Infect Dis 39: 1396-1397; author reply 1397-1398.

15. Forsyth PA, DeAngelis LM (1996) Biology and management of AIDS-associated primary CNS lymphomas. Hematol Oncol Clin North Am 10: 1125-1134.

16. Gray F, Gherardi R, Scaravilli F (1988) The neuropathology of the acquired immune deficiency syndrome (AIDS). A review. Brain 111: 245-266.

17. Pluda JM, Venzon DJ, Tosato G, Lietzau J, Wyvill K, et al. (1993) Parameters affecting the development of non-Hodgkin's lymphoma in patients with severe human immunodeficiency virus infection receiving antiretroviral therapy. J Clin Oncol 11: 1099-1107.

18. Raez LE, Patel P, Feun L, Restrepo A, Raub WA Jr, et al. (1998) Natural history and prognostic factors for survival in patients with acquired immune deficiency syndrome (AIDS)-related primary central nervous system lymphoma (PCNSL). Crit Rev Oncog 9: 199-208.

19. Johnson BA, Fram EK, Johnson PC, Jacobowitz R (1997) The variable MR appearance of primary lymphoma of the central nervous system: comparison with histopathologic features. AJNR Am J Neuroradiol 18: 563-572.

20. Thurnher MM, Rieger A, Kleibl-Popov C, Settinek U, Henk C, et al. (2001) Primary central nervous system lymphoma in AIDS: a wider spectrum of CT and MRI findings. Neuroradiology 43: 29-35

21. Goldstein JD, Dickson DW, Moser FG, Hirschfeld AD, Freeman K, et al. (1991) Primary central nervous system lymphoma in acquired immune deficiency syndrome. A clinical and pathologic study with results of treatment with radiation. Cancer 67: 2756-2765

22. Slone HW, Blake JJ, Shah R, Guttikonda S, Bourekas EC (2005) CT and MRI findings of intracranial lymphoma. AJR Am J Roentgenol 184: 1679-1685.

23. Mohile NA, Deangelis LM, Abrey LE (2008) The utility of body FDG PET in staging primary central nervous system lymphoma. Neuro Oncol 10: 223-228.

24. Schoder H, Noy A, Gonen M, Weng L, Green D, et al. (2005) Intensity of 18fluorodeoxyglucose uptake in positron emission tomography distinguishes between indolent and aggressive non-Hodgkin's lymphoma. J Clin Oncol 23 4643-4651.

25. Spaepen K, Stroobants S, Dupont P, Van Steenweghen S, Thomas J, et al. (2001) Prognostic value of positron emission tomography (PET) with fluorine-18 fluorodeoxyglucose ([18F]FDG) after first-line chemotherapy in non-Hodgkin's 
lymphoma: is [18F]FDG-PET a valid alternative to conventional diagnostic methods? J Clin Oncol 19: 414-419

26. So YT, Beckstead JH, Davis RL (1986) Primary central nervous system lymphoma in acquired immune deficiency syndrome: a clinical and pathological study. Ann Neurol 20: 566-572.

27. Camilleri-Broet S, Davi F, Feuillard J, Seilhean D, Michiels JF, et al. (1997) AIDSrelated primary brain lymphomas: histopathologic and immunohistochemical study of 51 cases. The French Study Group for HIV-Associated Tumors. Hum Pathol 28: 367-374.

28. Larocca LM, Capello D, Rinelli A, Nori S, Antinori A, et al. (1998) The molecular and phenotypic profile of primary central nervous system lymphoma identifies distinct categories of the disease and is consistent with histogenetic derivation from germinal center-related B cells. Blood 92: 1011-1019.

29. MacMahon EM, Glass JD, Hayward SD, Mann RB, Becker PS, et al. (1991) Epstein-Barr virus in AIDS-related primary central nervous system lymphoma. Lancet 338: 969-973.

30. Cinque P, Brytting M, Vago L, Castagna A, Parravicini C, et al. (1993) EpsteinBarr virus DNA in cerebrospinal fluid from patients with AIDS-related primary lymphoma of the central nervous system. Lancet 342: 398-401.

31. Arribas JR, Clifford DB, Fichtenbaum CJ, Roberts RL, Powderly WG, et al (1995) Detection of Epstein-Barr virus DNA in cerebrospinal fluid for diagnosis of AIDS-related central nervous system lymphoma. J Clin Microbiol 33: 15801583.

32. De Luca A, Antinori A, Cingolani A, Larocca LM, Linzalone A, et al. (1995) Evaluation of cerebrospinal fluid EBV-DNA and IL-10 as markers for in vivo diagnosis of AIDS-related primary central nervous system lymphoma. $\mathrm{Br} J$ Haematol 90: 844-849.

33. Cinque P, Vago L, Dahl H, Brytting M, Terreni MR, et al. (1996) Polymerase chain reaction on cerebrospinal fluid for diagnosis of virus-associated opportunistic diseases of the central nervous system in HIV-infected patients. AIDS 10: 951 958.

34. Brink NS, Sharvell Y, Howard MR, Fox JD, Harrison MJ, et al. (1998) Detection of Epstein-Barr virus and Kaposi's sarcoma-associated herpesvirus DNA in CSF from persons infected with HIV who had neurological disease. J Neurol Neurosurg Psychiatry 65: 191-195.

35. Tachikawa N, Goto M, Hoshino Y, Gatanaga H, Yasuoka A, et al. (1999) Detection of Toxoplasma gondii, Epstein-Barr virus, and JC virus DNAs in the cerebrospinal fluid in acquired immunodeficiency syndrome patients with focal central nervous system complications. Intern Med 38: 556-562.

36. Hirsch HH, Meylan PR, Zimmerli W, Iten A, Battegay M, et al. (1998) HIV1-infected patients with focal neurologic signs: diagnostic role of PCR for Toxoplasma gondii, Epstein-Barr virus, and JC virus. Clin Microbiol Infect 4 $577-584$

37. Rojanawiwat A, Miura T, Thaisri H, Pathipvanich P, Umnajsirisuk S, et al. (2005) Frequent detection of Epstein-Barr Virus and cytomegalovirus but not JC virus DNA in cerebrospinal fluid samples from human immunodeficiency virusinfected patients in northern Thailand. J Clin Microbiol 43: 3484-3486.

38. Ivers LC, Kim AY, Sax PE (2004) Predictive value of polymerase chain reaction of cerebrospinal fluid for detection of Epstein-Barr virus to establish the diagnosis of HIV-related primary central nervous system lymphoma. Clin Infect Dis 38: $1629-1632$

39. Sunden B, Larsson M, Falkeborn T, Paues J, Forsum U, et al. (2011) Real-time PCR detection of Human Herpesvirus 1-5 in patients lacking clinical signs of a viral CNS infection. BMC Infect Dis 11: 220.

40. Uehira T (2008) HAART and NeuroAIDS (in Japanese). The 22nd annua conference of The Japanese Society for AIDS Research.

41. Polilli E, Sozio F, Mazzotta E, Consorte A, Di Masi F, et al. (2010) Rapidly progressive and fatal EBV-related encephalitis in a patient with advanced HIV-1 infection at presentation: a case report and review of the literature. New Microbiol 33: 275-280.

42. Albany C, Psevdos G, Balderacchi J, Sharp VL (2011) Epstein-Barr virus myelitis and Castleman's disease in a patient with acquired immune deficiency syndrome: a case report. J Med Case Reports 5: 209.

43. Corcoran C, Rebe K, van der Plas H, Myer L, Hardie DR (2008) The predictive value of cerebrospinal fluid Epstein-Barr viral load as a marker of primary centra nervous system lymphoma in HIV-infected persons. J Clin Virol 42: 433-436.
44. Watanabe $\mathrm{D}$, Uehira $\mathrm{T}$, Yonemoto $\mathrm{H}$, Bando $\mathrm{H}$, Ogawa $\mathrm{Y}$, et al. (2010) Sustained high levels of serum interferon-gamma during HIV-1 infection: a specific trend different from other cytokines. Viral Immunol 23: 619-625.

45. Regidor DL, Detels R, Breen EC, Widney DP, Jacobson LP, et al. (2011) Effect of highly active antiretroviral therapy on biomarkers of B-lymphocyte activation and inflammation. AIDS 25: 303-314.

46. Ambinder RF, Bhatia K, Martinez-Maza O, Mitsuyasu R (2010) Cance biomarkers in HIV patients. Curr Opin HIV AIDS 5: 531-537.

47. Purdue MP, Lan Q, Bagni R, Hocking WG, Baris D, et al. (2011) Prediagnostic serum levels of cytokines and other immune markers and risk of non-hodgkin lymphoma. Cancer Res 71: 4898-4907.

48. Breen EC, Hussain SK, Magpantay L, Jacobson LP, Detels R, et al. (2011) B-cell stimulatory cytokines and markers of immune activation are elevated severa years prior to the diagnosis of systemic AIDS-associated non-Hodgkin B-cell lymphoma. Cancer Epidemiol Biomarkers Prev 20: 1303-1314.

49. Wong HL, Breen EC, Pfeiffer RM, Aissani B, Martinson JJ, et al. (2010) Cytokine signaling pathway polymorphisms and AIDS-related non-Hodgkin lymphoma risk in the multicenter AIDS cohort study. AIDS 24: 1025-1033.

50. Breen EC, Boscardin WJ, Detels R, Jacobson LP, Smith MW, et al. (2003) Non-Hodgkin's B cell lymphoma in persons with acquired immunodeficiency syndrome is associated with increased serum levels of IL10, or the IL10 promoter -592 C/C genotype. Clin Immunol 109: 119-129.

51. Whitcup SM, Stark-Vancs V, Wittes RE, Solomon D, Podgor MJ, et al. (1997) Association of interleukin 10 in the vitreous and cerebrospinal fluid and primary central nervous system lymphoma. Arch Ophthalmol 115: 1157-1160.

52. Fischer L, Korfel A, Pfeiffer S, Kiewe P, Volk HD, et al. (2009) CXCL13 and CXCL12 in central nervous system lymphoma patients. Clin Cancer Res 15 5968-5973.

53. Murase S, Saio M, Andoh H, Takenaka K, Shinoda J, et al. (2000) Diagnostic utility of CSF soluble CD27 for primary central nervous system lymphoma in immunocompetent patients. Neurol Res 22: 434-442.

54. Gallo P, Sivieri S, Rinaldi L, Yan XB, Lolli F, et al. (1994) Intrathecal synthesis of interleukin-10 (IL-10) in viral and inflammatory diseases of the central nervous system. J Neurol Sci 126: 49-53.

55. Cobbers JM, Wolter M, Reifenberger J, Ring GU, Jessen F, et al. (1998) Frequent inactivation of CDKN2A and rare mutation of TP53 in PCNSL. Brain Pathol 8: 263-276.

56. Nakamura M, Sakaki T, Hashimoto H, Nakase H, Ishida E, et al. (2001) Frequen alterations of the $\mathrm{p} 14(\mathrm{ARF})$ and $\mathrm{p} 16$ (INK4a) genes in primary central nervous system lymphomas. Cancer Res 61: 6335-6339.

57. Gonzalez-Gomez P, Bello MJ, Arjona D, Alonso ME, Lomas J, et al. (2003) $\mathrm{CpG}$ island methylation of tumor-related genes in three primary central nervous system lymphomas in immunocompetent patients. Cancer Genet Cytogene 142: $21-24$.

58. Ferreri AJ, Dell'Oro S, Capello D, Ponzoni M, luzzolino P, et al. (2004) Aberran methylation in the promoter region of the reduced folate carrier gene is a potential mechanism of resistance to methotrexate in primary central nervous system lymphomas. $\mathrm{Br} \mathrm{J}$ Haematol 126: 657-664.

59. Zhang SJ, Endo S, Saito T, Kouno M, Kuroiwa T, et al. (2005) Primary malignan lymphoma of the brain: frequent abnormalities and inactivation of p14 tumo suppressor gene. Cancer Sci 96: 38-41.

60. Nakamura M, Ishida E, Shimada K, Nakase H, Sakaki T, et al. (2006) Defective expression of HRK is associated with promoter methylation in primary central nervous system lymphomas. Oncology 70: 212-221.

61. Schwindt $H$, Vater I, Kreuz M, Montesinos-Rongen M, Brunn A, et al. (2009) Chromosomal imbalances and partial uniparental disomies in primary central nervous system lymphoma. Leukemia 23: 1875-1884

62. Makino K, Nakamura H, Hide TI Kuratsu JI (2012) Salvage treatment with temozolomide in refractory or relapsed primary central nervous system lymphoma and assessment of the MGMT status. J Neurooncol 106: 155-160.

63. Chu LC, Eberhart CG, Grossman SA, Herman JG (2006) Epigenetic silencing of multiple genes in primary CNS lymphoma. Int J Cancer 119: 2487-2491.

64. Herman JG (2004) Circulating methylated DNA. Ann N Y Acad Sci 1022: 33-39. 
Citation: Watanabe D, Koizumi Y, Yajima K, Uehira T, Shirasaka T (2011) Diagnosis and Treatment of AIDS-Related Primary Central Nervous Lymphoma. J Blood Disord Transfus S1:001. doi:10.4172/2155-9864.S1-001

65. Belinsky SA, Nikula KJ, Palmisano WA, Michels R, Saccomanno G, et al. (1998) Aberrant methylation of $\mathrm{p} 16$ (INK4a) is an early event in lung cancer and a potential biomarker for early diagnosis. Proc Natl Acad Sci U S A 95: 1189111896

66. Hoque MO, Topaloglu O, Begum S, Henrique R, Rosenbaum E, et al. (2005) Quantitative methylation-specific polymerase chain reaction gene patterns in urine sediment distinguish prostate cancer patients from control subjects. J Clin Oncol 23: 6569-6575.

67. Lavon I, Refael M, Zelikovitch B, Shalom E, Siegal T (2010) Serum DNA can define tumor-specific genetic and epigenetic markers in gliomas of various grades. Neuro Oncol 12: 173-180.

68. Liu BL, Cheng JX, Zhang W, Zhang X, Wang R, et al. (2010) Quantitative detection of multiple gene promoter hypermethylation in tumor tissue, serum, and cerebrospinal fluid predicts prognosis of malignant gliomas. Neuro Oncol 12: $540-548$

69. Weaver KD, Grossman SA, Herman JG (2006) Methylated tumor-specific DNA as a plasma biomarker in patients with glioma. Cancer Invest 24: 35-40.

70. Esteller M, Gaidano G, Goodman SN, Zagonel V, Capello D, et al. (2002) Hypermethylation of the DNA repair gene $O(6)$-methylguanine DNA methyltransferase and survival of patients with diffuse large B-cell lymphoma. J Natl Cancer Inst 94: 26-32.

71. Alizadeh AA, Eisen MB, Davis RE, Ma C, Lossos IS, et al. (2000) Distinct types of diffuse large B-cell lymphoma identified by gene expression profiling. Nature 403: 503-511.

72. Rosenwald A, Wright G, Chan WC, Connors JM, Campo E, et al. (2002) The use of molecular profiling to predict survival after chemotherapy for diffuse large-Bcell lymphoma. N Engl J Med 346: 1937-1947.

73. Shaknovich R, Geng H, Johnson NA, Tsikitas L, Cerchietti L, et al. (2010) DNA methylation signatures define molecular subtypes of diffuse large B-cell lymphoma. Blood 116: e81-89.

74. Richter J, Ammerpohl O, Martin-Subero JI, Montesinos-Rongen M, Bibikova M, et al. (2009) Array-based DNA methylation profiling of primary lymphomas of the central nervous system. BMC Cancer 9: 455.

75. Capello D, Scandurra M, Poretti G, Rancoita PM, Mian M, et al. (2010) Genome wide DNA-profiling of HIV-related B-cell lymphomas. Br J Haematol 148: 245 255
76. Rossi D, Gaidano G, Gloghini A, Deambrogi C, Franceschetti S, et al. (2003) Frequent aberrant promoter hypermethylation of O6-methylguanineDNA methyltransferase and death-associated protein kinase genes in immunodeficiency-related lymphomas. Br J Haematol 123: 475-478.

77. Calin GA, Croce CM (2006) MicroRNA signatures in human cancers. Nat Rev Cancer 6: 857-866.

78. Thapa DR, Li X, Jamieson BD, Martinez-Maza O (2011) Overexpression of microRNAs from the miR-17-92 paralog clusters in AIDS-related non-Hodgkin's lymphomas. PLoS One 6: e20781.

79. Baraniskin A, Kuhnhenn J, Schlegel U, Chan A, Deckert M, et al. (2011) Identification of microRNAs in the cerebrospinal fluid as marker for primary diffuse large B-cell lymphoma of the central nervous system. Blood 117: 3140 3146 .

80. Illerhaus G, Batchelor T (2011) PCNSL: biomarker better than biopsy? Blood 117: $2987-2989$

81. Fine HA, Mayer RJ (1993) Primary central nervous system lymphoma. Ann Intern Med 119: 1093-1104

82. Formenti SC, Gill PS, Lean E, Rarick M, Meyer PR, et al. (1989) Primary centra nervous system lymphoma in AIDS. Results of radiation therapy. Cancer 63 1101-1107.

83. Baumgartner JE, Rachlin JR, Beckstead JH, Meeker TC, Levy RM, et al. (1990) Primary central nervous system lymphomas: natural history and response to radiation therapy in 55 patients with acquired immunodeficiency syndrome. $J$ Neurosurg 73: 206-211.

84. Skiest DJ, Crosby C (2003) Survival is prolonged by highly active antiretrovira therapy in AIDS patients with primary central nervous system lymphoma. AIDS 17: $1787-1793$

85. Jacomet C, Girard PM, Lebrette MG, Farese VL, Monfort L, et al. (1997) Intravenous methotrexate for primary central nervous system non-Hodgkin's lymphoma in AIDS. AIDS 11: 1725-1730.

86. Aboulafia DM Puswella AL (2007) Highly active antiretroviral therapy as the sole treatment for AIDS-related primary central nervous system lymphoma: a case report with implications for treatment. AIDS Patient Care STDS 21: 900-907. 